\title{
Bioética em Saúde Pública
}

\author{
Bioethics in Public Health
}

Um dos desafios ao administrador público, no queserefere ao binômio CidadãoEstado, inclusive nos campos da assistência médica, farmacêutica e social, diz respeito às diferenças, conceituais e práticas, existentes entre os modelos da assistência individual e coletiva.

A Bioética tem oferecido subsídios teóricos e práticos para dirimir conflitos de interesses e valores que mais e mais se apresentam na administração da saúde pública, entendida aqui no sentido de saúde coletiva, da responsabilidade do poder público; e não apenas aquela prestada por órgãos próprios do governo - concepção esta que permeia a concepção de muitos brasileiros.

Por isso, torna-se imprescindível relembrar o que representa o Sistema de Saúde - SUS, no contexto do sistema de saúde brasileiro, visto que seus princípios fundamentais da Universalidade de cobertura, I gualdade de acesso e Integralidade da assistência constituem princípios de alto teor bioético que permitem estabelecer as bases de uma gestão moralmente legítima e socialmente aceitável.

Esses três princípios fundamentais encontram-se, não em obrigatória correspondência, com as bases filosóficas dos dilemas éticos da saúde pública, em qualquer lugar do mundo, quais sejam o de racionalizar os recursos, sempre finitos; o de influenciar as pessoas a mudarem atitudes nefastas à saúde; e o de limitar a liberdade individual para se ter a diminuição de doenças transmissíveis.

Por sua vez, esses dilemas buscam ser resolvidos por diversas correntes filosóficas, tanto as que enfocam o indivíduo, - a exemplo do Utilitarismo (que defende posições basicamente fundadas na otimização das conseqüências ou resultados para todos os envolvidos numa disputa) e do Liberalismo (que prioriza os direitos fundamentais da pessoa e a garantia de acesso individual ao mesmo tipo de oportunidades), como a que visa à coletividade - a exemplo do Comunitarismo (que prioriza as "comunidades" de interesses e valores dos vários agentes morais e tenta articulá-las pelo mútuo reconhecimento). As diferentes posições e visões concorrem para a necessidade de outras discussões, entre as quais destacam-se aquelas sobre se o direito à saúde significa somente 0 direito à assistência aos doentes; sobre o peso do financiamento dos diversos setores e áreas envolvidas com a promoção da saúde e a prevenção e o controle de doenças; e sobre as duas práticas assistenciais existentes, uma baseada na Ética M édica (da relação médicopaciente) e a outra, ainda pouco conhecida e absorvida pelos profissionais da saúde, baseada na Bioética da Saúde Pública (das responsabilidades institucional e governamental para com o bem-estar das populações humanas em seus respectivos contextos bio-sociais).

As discussões mostram, em última análise, a necessidade de o Governo oferecer 0 mínimo de quantidade e qualidade de vida para todos e prover a assistência à saúde para garantir esse mínimo.

Isso porque o D ireito é inseparável da M oral, da mesma forma que da Economia e da Sociologia. Com efeito, a aspiração dos cidadãos das sociedades complexas e multiculturais contemporâneas por vários tipos de bens razoáveis e legítimos, inclusive aqueles relacionados à sua saúde (considerada 
por muitos como condição necessária para a obtenção de outros bens e inscrita na própria sabedoria popular quando afirma que "o importante é ter boa saúde"), faz com que tais sociedades possuam várias esferas legítimas de justiça, cada uma definida pela proteção de um bem considerado fundamental: saúde, segurança, educação, trabalho, etc. No entanto, devido à própria dinâmica competitiva desse tipo de sociedade, existe nelas também a tendência a criar esferas de monopólio e domínio dentro do tecido social, sendo um dever do Estado democrático evitar o predomínio de uma única esfera sobre as demais.

U m ponto já estabelecido da ética na área da saúde, e certamente por conta da urgência demandada pela pesquisa envolvendo seres humanos, é o da autonomia do indivíduo, devida e esclarecidamente informado, para escolher entre as opões diagnósticas ou terapêuticas que lhe são apresentadas. Porém, a autonomia é uma competência para agir em total independência pelo indivíduo, que, para se efetivar, precisa ter o poder efetivo de agir (isto é, de exercitar direitos) reconhecido por uma capacidade jurídica (isto é, de gozo de direitos). Q uando exercida em um contexto social específico, a autonomia faz com que se choquem o direito individual e 0 direito coletivo, o que em muitos casos pode traduzir-se também como choque entre as práticas médicas individual e institucional.

Voltando à importância do contexto em que se dão essas práticas: a individual, atual mente praticada em consultórios, clínicas ou hospitais sob os auspícios de empresas privadas ou corporativas de assistência médico-hospitalar, geralmente mostra-se compartimentada, pulverizada e de cobertura parcial de procedimentos; e a verdadeiramente institucional, que prima, no estabelecimento de seus processos e condutas, pela integralidade assistencial dada pela integração de serviços oferecidos e prestados. Q uando de natureza pública (seja direta ou, se entidade privada credenciada para a prestação de serviço público, indireta), estabelece-se também 0 pacto moral da igualdade de acesso. A concomitância dessas práticas, seja por parcialidade de cobertura assistencial privada ou corporativa, seja por difícil acesso às unidades de saúde do sistema público, próprias ou privadas, pode colocar um mesmo indivíduo na situação do conflito que se dá entre essas duas práticas. Ele, então, pela concepção individualista e individualizada da sua necessidade, passa a querer o direito da prática individual no âmbito institucional - 0 que o faz apelar para o reconhecimento jurídico desse direito.

Esse reconhecimento, quando juridicamente determinado, cria para o administrador público o dilema de acatálo - contrapondose portanto a tudo o que rezam os princípios fundamentais do SUS e as normas e procedimentos que 0 estruturam e operacionalizam, inclusive as prerrogativas e responsabilidades dos seus gestores, ou de não acatá-lo - situando-se portanto fora da lei, com todo o ônus que isso comportaria.

Por conta dessas contradições, o que se tem observado é uma cobertura indireta do setor privado não ligado ao SUS por recursos públicos, mormente nas áreas da alta complexidade e principalmente no que se refere à dispensação de medicamentos de alto custo ou de uso contínuo. Com mais uma grave distorção que esse status quo causa: a quebra da eqüidade na alocação de recursos e no acesso dos cidadãos aos serviços financiados por recursos públicos.

$\mathrm{No}$ contexto estrutural, operacional e político, os conflitos bioéticos que temos vivido no Brasil dizem respeito às práticas assistenciais (prescrição médica versus ciência médica) que se dão a partir das interpretações dadas à Ciência M édica (ciência médica versus pesquisa médica) e à Pesquisa M édica, e à atual mescla entre esta última com a Assistência M édica.

No que tange à pesquisa, vem sendo publicamente proposto que uma Política de Ciência, Tecnologia el novação em Saúde deva ter como pressupostos essenciais a busca da eqüidade e a observância de rigorosos princípios bioéticos na pesquisa e na experimentação em geral. Também, que essa Política se estruture principalmente no compromisso do ganho social em todas suas vertentes - saúde, indústria, comércio ecultura científica -, na extensão do conhecimento e na abrangência de todos os que se envolvem com a pesquisa em saúde. 
A preocupação é pertinente porque, em todo 0 mundo, graves problemas vêm-se instalando e demandando dos governos novos mecanismos de avaliação para a incorporação tecnológica para aassistência médico-hospitalar de al ta complexidade e de al to custo em geral.

Como a Bioética da assistência oncológica também diz respeito à alocação de recursos, deve-se sempre ter em mente a seguinte seqüência lógica na avaliação econômica da assistência: (a) os recursos serão crescentemente finitos; (b) os avanços em ciência e tecnologia aumentam as possibilidades da assistência oncológica; (c) o contraste entre (a) e (b) demanda o estabelecimento de prioridades; (d) esse estabelecimento deve ser feito com atribuição de responsabilidades e com critérios explícitos; (e) a avaliação econômica completa deve ser a base para 0 necessário acordo sobre o estabelecimento de prioridades razoáveis e compartilháveis, não podendo-se esquecer que o câncer é uma doença que, por si só, impõe limitações e exigências, as quais, por sua vez, limitam a ação preventiva, diagnóstica ou terapêutica no contexto dos recursos efetivamente disponíveis.

Por isso, temos de conscientizar-nos de que a superação de conflitos éticos é dinâmico e envolve uma ampla interação de necessidades, obrigações e interesses dos vários envolvidos: 0 G overno, por ser 0 agente protetor, regulador, financiador e comprador maior; a Indústria e os Fornecedores, que exercem grande pressão inflacionária, para a incorporação dos seus produtos ou bens; as Instituições e os Profissionais da Saúde, que pressionam pela atualização da sua capacidade instalada, variedade de oferta de serviços e atualização técnico-científica; e os D oentes, por exigirem, nem sempre com a informação adequada e o necessário poder crítico ou de discernimento, o que se Ihes apresenta como solução para o seu mal-estar.

Por conta disso é que os financiadores e administradores, que sempre dispõem de recursos finitos, são pressionados para incorporar novos e caros medicamentos e equipamentos. A colaboração entre as instituições de saúde e as autoridades judiciais e sanitárias ajuda a avaliar o desenvolvimento de novas tecnologias e estabelecer a validade e prioridades para a sua incorporação. Os obstáculos ao entendimento incluem os diferentes valores dados aos métodos e resultados de pesquisas, falta de diretrizes nacionais e um baixo investimento extragovernamental em serviços oncológicos.

Temos de decidir: queremos prevenir e detectar doenças e incluir um maior número de indivíduos, diagnosticando-os e tratandoos adequadamente, com a maior relação benefício/custo estabelecida, ou queremos, com os mesmos recursos, continuar tratando, por vezes futilmente, um número bem menor de indivíduos?

Esta questão não só implica uma decisão à luz da Bioética, mas, também, uma oportunidade de se aprimorar a relação entre meios e fins que caracteriza o crescimento técnico-científico capaz de desenvolver soluções para os nossos próprios problemas. Pois continuar aplicando e consumindo procedimentos ofertados, apenas esperando a confirmação de erros e acertos, por incorporação passiva dessa oferta, em nada nos fará autores de nossa própria história médica e de saúde pública.

Jacob Kligerman Diretor Geral Instituto N acional de Câncer M inistério da Saúde Kligerman@inca.gov.br

Gambia Government/M edical Research C ouncil J oint Ethical Committee Ethical issuesfacing medical research in developing countries. Lancet 1998; 351:286-7.

Guimarães R. Política de Ciência, Tecnologia e Inovação em Saúde. Jornal da Ciência - JC email.htm, 02/08/2002 e 13/08/2002.

$M$ archi M M . AutonomiaeH eteronomianaRelação entreProfissional deSaúdeeU suário dos Serviços de Saúde. http://200.239.45.3/cfm/espelho/ revista/biolv6/autoheter.htm

Roberts M J, Reich M R. Ethical analysisin public health. Lancet 2002; 359: 1055-59.

Schramm FR. Considerações sobre o conceito de eqüidade. Subsídios para o Conselho de Bioética do IN CA. 24/08/1999. (mimeo) 